\title{
Forms and status of sulphur availability in soils of Mizoram
}

BRAJENDRA, A. K. VISHWAKARMA AND MEGHNA SARMA

MEMBERS OF RESEARCH FORUM:

Corresponding author : BRAJENDRA, ICAR-Indian Institute of Rice Research, HYDERABAD (TELANGANA) INDIA

Co-authors :

A.K.VISHWAKARMA, ICAR-Indian Institute of Soil Science, BHOPAL (M.P.) INDIA

MEGHNA SARMA, ICAR Research Complex for North Eastern Hill Region, UMIAM (MEGHALAYA) INDIA

Received : 28.01.2016; Revised : 20.04.2016; Accepted : 16.05 .2016

\section{Summary}

Block level samples were collected from surface $(0-15 \mathrm{~cm}$ depth) soils under major land use systems of Mizoram. Different forms of sulphur, their availability status were inventorized. Surface samples from all the RBDs of Mizoram were analyzed developed under different land forms and land use. Thirty six per cent soils sampled were medium in available sulphur status (10 ppm - $30 \mathrm{ppm})$. Thirty five per cent soils sampled were found to be low in available sulphur $(<10 \mathrm{ppm})$. Twenty nine per cent soils sampled were found to be high $(>30 \mathrm{ppm})$. Status of available sulphur was found to be medium in most of the soils.

Key words : Forms of Sulphur, Availability

How to cite this article : Brajendra, Vishwakarma, A.K. and Sarma, Meghna (2016). Forms and status of sulphur availability in soils of Mizoram. Asian J. Soil Sci., 11 (1) : 197-201 : DOI : 10.15740/HAS/ AJSS/11.1/197-201. 